\title{
Fragment memories mark the end of childhood amnesia
}

\author{
DARRYL BRUCE and L. AMBER WILCOX-O'HEARN \\ Saint Mary's University, Halifax, Nova Scotia, Canada \\ JOHN A. ROBINSON \\ University of Louisville, Louisville, Kentucky \\ KIMBERLY PHILLIPS-GRANT and LORI FRANCIS \\ Saint Mary's University, Halifax, Nova Scotia, Canada \\ and \\ MARILYN C. SMITH \\ University of Toronto, Scarborough, Ontario, Canada
}

\begin{abstract}
Adults described and dated two kinds of first remembrances: a personal event memory (the recollection of a personal episode that had occurred at some time in some place) and a memory fragment (an isolated memory moment having no event context and remembered, perhaps, as an image, a behavior, or an emotion). First fragment memories were judged to have originated substantially earlier in life than first event memories-approximately $31 / 3$ years of age for first fragment memories versus roughly 4 years of age for first event memories. We conclude that the end of childhood amnesia is marked not by our earliest episodic memories, but by the earliest remembered fragments of childhood experiences.
\end{abstract}

Childhood amnesia may be defined as deficient recall by adults of personal experiences from early in life (Wetzler \& Sweeney, 1986). The research to be described is concerned with when childhood amnesia ends and with the kinds of memories that mark its demise. These are problems of long-standing interest to psychologists (e.g., Miles, 1893), and they have been addressed in one of two ways. In one approach, subjects recall, with or without cues, personal events from their pasts-sometimes the earliest retrievable event (e.g., Mullen, 1994), sometimes events from a range of childhood years (e.g., Waldfogel, 1948), and sometimes events from any time in the past (e.g., Rubin, 1982) - and then estimate how old they were at the time. A second method is to request that adults furnish details about childhood personal events that happened at known times - for instance, the birth of a younger sibling (e.g., Eacott \& Crawley, 1998).

An important quantitative outcome of these studies is that the earliest age from which an adult can retrieve a personal memory is typically between 3 and 4 years. Es-

Financial support was provided by grants from the Social Sciences and Humanities Research Council of Canada and from the Faculty of Graduate Studies and Research, Saint Mary's University. L.A.W.-O. is now at the Department of Computer Science, University of Toronto. K.P.-G. is now at the Department of Psychology and Research in Education, University of Kansas. We thank Stephen Lindsay, Eugene Winograd, and the journal reviewers for helpful comments on an earlier version of the article. Address correspondence to D. Bruce, Department of Psychology, Saint Mary's University, Halifax, NS, B3H 3C3 Canada (email:dbruce@husky1.stmarys.ca). timates vary rather widely, however. In a recent review of the literature, Malinoski, Lynn, and Sivec (1998) reported that mean age judgments of first memories ranged from 3.01 to 6.15 years. One factor contributing to this variability is the nature of the event being recalled. For example, Eacott and Crawley (1998) observed that subjects could retrieve autobiographical information associated with the birth of a sibling even if they were only $2-3$ years old at the time. Variations of this sort aside, the general picture that has emerged is that enduring event memories of childhood begin to be created between ages 3 and 4 and become increasingly frequent as the years advance. By about age 7, the retention of autobiographical experiences is commensurate with what would be expected if nothing more than normal forgetting were operating (e.g., Rubin, 2000). Viewed from the other side of the fence, childhood amnesia blankets the first 3 years of life, begins to decline for events that occurred sometime between ages 3 and 4, and is largely over around age 7 .

Inferring childhood amnesia from a level of event memory over the childhood years that is less than what normal forgetting would predict (e.g., Rubin, 1982; Wetzler \& Sweeney, 1986) is an indirect approach to the phenomenon. In an earlier investigation (Bruce, Dolan, \& Phillips-Grant, 2000), we attempted to assess it more directly. Subjects were asked to describe and date two personal events from the first 8 years of their lives: one that they could recollect (a remember event) and one that they could not remember but knew had happened because of information obtained from parents, photos, or some other 
external source (a know event). ${ }^{1}$ We anticipated that as the childhood years increased from 0 to 8 , the frequency of know events would decrease-a direct indication of waning childhood amnesia-whereas the frequency of remember events would increase, reflecting the emergence of remembrances of early life and, indirectly, the decline of childhood amnesia. This outcome was obtained, but we were puzzled by the large difference between the mean estimated age of occurrence of remembered events (5.85 years) and that of known events ( 3.35 years). On the view that the two age distributions are reciprocal indications of diminishing childhood amnesia, we had expected that they would be approximately the complement of each other and would have similar means.

The present experiments were an effort to explain the substantial separation between the age distributions for know and remember events. We conjectured that the gap might have something to do with two different kinds of first memories. One we shall call fragment memories or, alternatively, memory fragments; the other we shall term episodic or event memories. The distinction can best be appreciated by an example of each kind of remembrance. First, an episodic memory. This is from a male participant in a study of first remembrances by Dudycha and Dudycha (1933b). It is quite representative of other first memories reported verbatim in that article and in a companion piece (Dudycha \& Dudycha, 1933a):

My first spell of anger, which I can remember, was when I was four years old, on my fourth birthday. My aunt sang a great deal and had taught me many quite long songs. This day my father wanted me to sing for him, but I refused because I had been ill and could hardly speak. He grew quite angry when I refused, but I didn't think anything of it. In about five minutes he asked me again and I refused so he sent me to bed. That was even before sunset and I really remember having called my father a fool. I was so angry I couldn't cry. (Dudycha \& Dudyucha, 1933b, p. 275)

An example of a memory fragment is the following excerpt from the painter Georgia O'Keeffe's (1977) autobiography:

My first memory is of the brightness of light-light all around. I was sitting among pillows on a quilt on the ground - very large white pillows. The quilt was a cotton patchwork of two different kinds of material — white with very small red stars spotted over it quite close together, and black with a red and white flower on it. I was probably eight or nine months old. (p. 1)

The differences between the two kinds of memory are easily identified. The male subject's recollection of his first spell of anger exemplifies what we mean by an event or an episodic memory. Actually, it is a recollection of more than a single event. It is a narrative or a story that contains a number of connected events: refusing to sing for his father, refusing a second time and being sent to bed, calling his father a fool, and being so angry that he couldn't cry. Because personal memories often comprise sets of related events (Robinson, 1992b), labeling them general events, as Conway has (e.g., Conway \& Pleydell-Pearce, 2000), may well be preferable. But we shall stick to calling them episodic or event memories. There is another feature that distinguishes such remembrances: They have a context, a setting, or some background - in the example given, the fact that it was the subject's fourth birthday, that his aunt had taught him many songs, and that he had been ill before his birthday.

In a fragment memory, by contrast, these features are absent, or at least not so prominent. Georgia O'Keeffe's (1977) recollection is illustrative. It is a description of an isolated moment in time; in her case, it is a highly detailed visual image of a scene. It has little or no context. We can hardly call it an episode or an event - in other words, a happening that is part of an ongoing sequence of happenings (see Tulving, 1983, pp. 142-143, for a discussion of the two terms). And it is certainly not a narrative or a storylike memory.

O'Keeffe's (1977) early memory fragment is not unusual. Memories of childhood recounted by the writers Vladimir Nabokov (1966), Esther Salaman (1970), and Virginia Woolf (1976) and the scientist E. O. Wilson (1994) are also not narratives. Many of them are noncontextualized, stand-alone snippets of the past that are recollections of sensory experiences (images of a visual, auditory, olfactory, or other sensory nature), behaviors or actions, or feelings or emotions. Others before us have written in a similar vein about such remembrances. Salaman referred to them as "fragment memories" (p. 40) and "memories of particular moments" (p. 31). She likened each to "an island without a background" (p. 33). Robinson (1992a) characterized them as moments that "are isolated from a temporal sequence of related events" (p. 228), and Kotre (1995) as "shards of remembrance" (p. 192) from our earliest years.

There is virtually no scientific evidence bearing on such impressions. To our knowledge, the only pertinent data have been collected by Mullen (1994). In her investigation, she found that $15 \%$ of her respondents' earliest memories were fragments (she called them images), the remainder being event memories. What especially intrigued us was the possibility that first fragment memories may stem from earlier in life than first event memories. Note that Georgia O'Keeffe's (1977) remembrance quoted above was of an experience prior to age 1 ! More persuasive is Mullen's finding that the earliest fragment recollections in her investigation were of experiences judged to have occurred about age 3 , roughly 4 months earlier, on average, than the datings given to the earliest memories of events. We believe that the reason for this is rooted in what we perceive to be the relation between fragment and event memories-namely, fragments are ordinarily the constituent details of event remembrances. In other words, event knowledge usually provides a context for fragments. When fragment memories arise in very early childhood, however, language, narrative, social interaction, and other cognitive skills may not have developed sufficiently to permit the creation of a context 
in which specific fragments would normally reside. Thus, childhood fragment memories can precede the formation of our earliest, more complete, event memories. Furthermore, they may occasionally endure and be retrievable in adulthood as isolated memory moments.

The primary hypothesis of this research, then, is that if subjects were to recount and date two kinds of first memories (fragment and event memories), fragments would, on balance, come from earlier in life than event memories. If so, it would suggest that first fragment memories are precursors of our earliest event memories. How is this related to an explanation of the separation between the age distributions of known and remembered events obtained by Bruce et al. (2000)? Simply that there might have been no separation had we compared distributions of estimated ages for known events and for first fragment memories.

\section{EXPERIMENT 1}

Before proceeding to a test of our primary hypothesis, we first will consider a more prosaic reason for the gap between the two age distributions in Bruce et al.'s (2000) investigation. In that study, subjects described and dated remembered events from the first 8 years of their lives. But suppose the subjects were asked to describe and date the earliest events that they could remember. Would this eliminate the age difference between know and remember experiences? If so, it would indicate that fragment memories, if indeed they exist, have nothing to do with the separation between the two distributions. In Experiment 1 , we sought to answer this question and to replicate the basic finding of Bruce et al.'s investigation.

\section{Method}

Subjects. The subjects were 282 students enrolled in introductory psychology courses at Saint Mary's University. All received course bonus points for participating in the study.

Procedure and Design. Access to the study was via the Internet. The subjects were given the URL for the investigation and logged on at any computer that had Internet access. After providing informed consent, they furnished some biographical information. They then described two childhood experiences: one that they could actually remember (a remember event) and another that they knew about only from an external source (a know event). After each report, they estimated how old they were at the time and indicated their confidence in their estimates.

There were two instructional conditions: The subjects recalled a personal event from any time during the first 8 years of their lives, or they recalled the earliest personal event that they could remember. In both conditions, the know event was to be from the first 8 years of childhood. For the remembered event, the subjects were told that it should be "a personal memory of something that happened to you or that you experienced at some time in some place. You are able to become consciously aware again of some aspects of the event, of what happened, or of what you experienced at the time. Perhaps you have an image of the event or you can reexperience one or more specific details about its occurrence." For the know report, the subjects were instructed to describe an event that "you know ... happened to you at some time in some place, but you cannot consciously recollect any aspect of the event's occurrence, of what happened, or of what you experienced at the time. Instead, your knowledge of the event comes from an external source. Perhaps you learned of it from your parents or other family members, friends, pictures, photo albums, diaries, or family stories. In your report, please indicate how you know about the event." For both remembered and known events, the subjects were cautioned that they should be incidents that occurred once, not repeatedly.

Each set of instructions concluded with an example of what was being requested. For the subjects asked to report an event from the first 8 years of life, the example was the following. "I remember going to the beach with my family. It was a beautiful day and we had a picnic. We all spent most of the day making a gigantic sand snake. It curled every which way for about 20 feet from the edge of the water. Eventually the tide came in and destroyed it, but it looked great while it lasted." The example was the same for the subjects asked to remember the earliest event of their lives, except that the first sentence was altered slightly: "My earliest personal event memory is of going to the beach with my family." The illustration of a know event was "I don't remember doing this, but my sister says that one time when she babysat me, I cried the entire time, and after two hours, she finally had to call our parents home."

After describing an event, the subjects were shown a horizontal time scale with the label "Age in years at the time of the event" above it. Major divisions of the scale were in years and had the numbers $0-8$ directly below them. Minor tick marks divided each 1 -year interval into 2-month periods. An age estimate was made by clicking with the mouse at a point on the scale that corresponded to the judged age of the subject at the time of the event. To help the subjects in this task, they were advised to relate the event to something that they knew had happened to them at a particular childhood age. After making their estimates, the subjects gave a confidence judgment by pointing at and clicking on one of five graded statements ranging from certain of my age at the time (1) to not at all sure of my age at the time (5).

Event reports and final sample of subjects. The 564 event descriptions ( 2 per subject) were subjected to a validity check. The reports were randomly ordered, and their identity (remember or know event) was concealed. Each was independently evaluated by two of the authors (D.B. and J.A.R.) as to whether it was a remember event, a know event, or neither. Classifications were made in light of the instructional criteria given to the subjects. The judges initially agreed on $92.4 \%$ of the reports; differences on the remaining reports were resolved by discussion. The end result was that 77 reports were rejected for the following reasons: 39 were accounts of repeated events, 14 were know events that were deemed to be remember events, 10 were considered to be autobiographical facts (e.g., "I have been told that I would only eat peas as a child"), 8 were ambiguous and could not be classified one way or another, and 6 were deemed inadmissible for a variety of other reasons. The 77 disqualified submissions were furnished by 71 subjects. The final set of data, then, was provided by 211 subjects and consisted of 422 event descriptions. Accounts of remember events were significantly longer than those of know events. The former contained 65.8 words, on average, and the latter 51.2 words $[F(1,209)=41.04$, $\left.M S_{\mathrm{e}}=554.16, p<.001\right]$. The length of a description was not significantly affected by the instructional manipulation $[F(1,209)<1]$, and there was no interaction of instructions and event type $\left[F(1,209)=1.36, M S_{\mathrm{e}}=554.16, p>.05\right]$.

Of the 211 subjects, 143 were females, and 68 were males. Events remembered from the first 8 years of childhood were furnished by 99 subjects, and earliest remembered events by 112 subjects. Report order was counterbalanced: 107 subjects recounted a remember event first, and 104 reported a know event first. The subjects ranged in age from 17.6 to 30.3 years, with a median age of 19.1 years.

\section{Results}

Age estimates and confidence judgments. Table 1 sets forth means and standard deviations of estimated event ages and associated confidence judgments in each 
Table 1

Experiment 1: Means and Standard Deviations of Age Estimates and Confidence Judgments for Remember (R) and Know (K) Events

\begin{tabular}{|c|c|c|c|c|c|c|c|c|}
\hline \multirow[b]{3}{*}{ Instruction } & \multicolumn{4}{|c|}{ Age } & \multicolumn{4}{|c|}{ Confidence } \\
\hline & \multicolumn{2}{|c|}{ R Event } & \multicolumn{2}{|c|}{ K Event } & \multicolumn{2}{|c|}{ R Event } & \multicolumn{2}{|c|}{ K Event } \\
\hline & $M$ & $S D$ & $M$ & $S D$ & $M$ & $S D$ & $M$ & $S D$ \\
\hline Remember 0-8 & 5.99 & 1.56 & 3.35 & 1.78 & 1.90 & 0.84 & 2.16 & 0.88 \\
\hline Remember earliest & 4.22 & 1.85 & 3.53 & 1.74 & 2.08 & 0.91 & 2.21 & 0.96 \\
\hline
\end{tabular}

of the four main conditions of the experiment. For age estimates, there were no main effects or interactions involving report order $[F(1,207) \leq 1.22, p>.05]$. There was a significant interaction of event type and instructions $\left[F(1,207)=36.36, M S_{\mathrm{e}}=2.74, p<.001\right]$, which supported our a priori intention to conduct simple effects tests. The simple effects tests revealed that the mean estimated age of know events was reliably lower than that of remember events, regardless of whether the subjects were instructed to report the earliest event that they could remember $\left[F(1,207)=9.86, M S_{\mathrm{e}}=2.74, p<.01\right]$ or one from the first 8 years of their lives $[F(1,207)=$ $\left.126.11, M S_{\mathrm{e}}=2.74, p<.001\right]$. Estimated ages of know events in the two instructional conditions were not significantly different $[F(1,410)<1]$.

Confidence in age estimates for know events was somewhat weaker than that for remember events $[F(1,207)=$ $\left.5.40, M S_{\mathrm{e}}=0.76, p<.05\right]$. There were no statistically significant effects from the order in which events were reported or the instructions concerning the recall of remembered events and no interactions involving these factors $\left[F(1,207) \leq 3.24, M S_{\mathrm{e}} \leq 0.86, p>.05\right]$.

Age distributions of remember and know events. Figure 1 presents cumulative relative frequency distributions for the ages of remember and know events. The horizontal axis is marked off in quarter-year intervals, and each data point is plotted at the top of the interval. For instance, the percentage of age estimates from 3.0 to 3.24 has been added to the percentage of cases just short of 3.0 - the top of the earlier interval-and plotted at 3.25 . The top of the age scale, by which point $100 \%$ of the cases are cumulated, is therefore 8.25.

Separate distributions are shown for the age of the earliest remembered event (Remember earliest) and the age of an event remembered from any point during the first 8 years of childhood (Remember 0-8). Because the instructions variable had no reliable effect on the estimated ages of know events, the data from the two instructional conditions have been combined into a single know distribution. The three functions are quite different: The distributions for events known and remembered from the first 8 years of childhood are widely separated, with median ages of 3.33 and 6.30 years, respectively. Intermediate, although closer to the function for know events, is the distribution for the earliest remembered events, with a median age of 3.87 years.

\section{Discussion}

Experiment 1 accomplished two things: First, it replicated the main finding of Bruce et al. (2000). In that study, the mean ages of know and remember events from the period of $0-8$ years were 3.35 and 5.85 years, respectively; in the present experiment, the corresponding means were 3.35 and 5.99 years. We note also that in a recent study in which middle-age subjects were used, Multhaup, Johnson, and Tetirick (2005) obtained mean age estimates of 3.57 and 5.43 years for remember and know events, respectively. Clearly, then, our original result is quite reliable. Second, asking the subjects to report and date first event memories, rather than memories from any time during the first 8 years of their lives, reduced the difference between the age distributions for remember and know events, but it did not entirely eliminate it. Thus, the failure to ask the subjects in our earlier research to provide their earliest episodic remembrances does not appear to be the entire explanation for the separation that we observed between the age distributions for know and remember memories.

\section{EXPERIMENT 2}

In this experiment, we take up our primary hypothesisnamely, that if subjects were to recall and date a first fragment and a first event memory, fragment memories would, on average, predate event memories. This would be consistent with the idea that the earliest retrievable memory fragments are precursors of adults' first event remembrances. It would also suggest that the separation remaining between the age distributions for know events and first event memories, as evidenced in Experiment 1, is a period between the offset of childhood amnesia and the onset of retrievable episodic memories from which fragmentary recollections are likely. Whether we should expect the age distribution for first fragment memories to coincide with that obtained in Experiment 1 for know events is debatable. It depends on how one views the relation between know events and first memories, a matter that we will take up in the General Discussion section.

\section{Method}

Subjects. The subjects were 185 students enrolled in introductory psychology courses at Saint Mary's University. They received a bonus point toward their final grades for taking part in the study.

Procedure and Design. The study was again carried out on the Web. The subjects entered, via the keyboard, some biographical information and then their earliest fragment and personal event memories. After each report, the subjects provided three sets of judgments: (1) how old they were at the time of the experience, (2) their confidence in their estimates (judgments of age and confidence were made as in Experiment 1), and (3) assessments of each memory on 20 seven-point scales (to be described presently). 


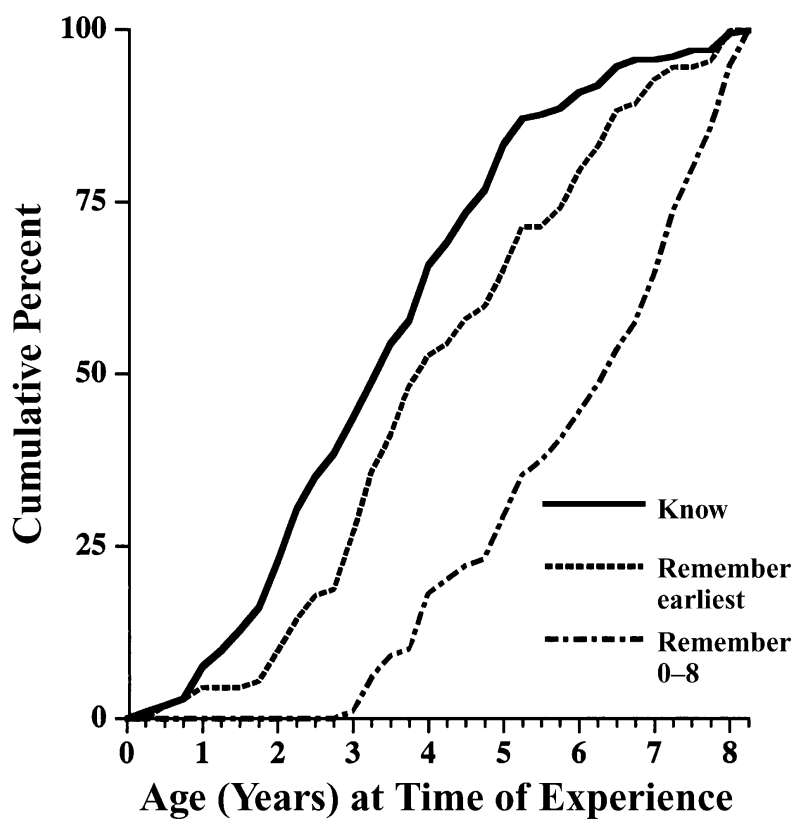

Figure 1. Experiment 1: cumulative relative frequency distributions for the ages of know events (Know), earliest remembered events (Remember earliest), and events remembered from the first 8 years of life (Remember $0-8$ ).

The instructions for an event memory asked the subjects to "describe the earliest personal event in your life that you can remember. The memory should be of something that happened to you or that you experienced at some time in some place. In other words, it is a story about an event or incident in your life that you can personally remember. So it has a beginning and an end and you will be able to recall some specific details about what happened." The fragment instructions were to "describe the earliest memory fragment in your life that you can remember. A memory fragment is not a story with a beginning and an end; it is simply a disconnected piece of memory. It lacks the continuity, background information, and details associated with a story about an event. Perhaps you remember it as an image (visual, auditory, or of a smell or taste), a behavior, or an emotion. In short, it is nothing more than an isolated fragment that sticks in your mind."

The subjects were cautioned that (1) the experiences that they described should be ones that they could actually remember and not ones that they merely knew had happened to them and (2) their reports should be of experiences that had occurred only once, not repeatedly. Each set of instructions was followed by an example of the kind of memory being requested. For an event memory, the example was identical to that used in the condition in Experiment 1 in which the subjects reported their earliest episodic memories. For a fragment recollection, it was "the earliest fragment of experience from my memory is of sitting on a sleigh in the winter and eating red licorice. I don't remember where it was or how I got the licorice."

The 20 seven-point scales used to rate the memories are presented in the Appendix. Most $(n=18)$ were selected from the items appearing in Johnson, Foley, Suengas, and Raye (1988) and were suitably modified for use in the present research; two (6 and 20) were newly constructed. The objective was to evaluate a variety of characteristics about the events and fragments that the subjects recalled, such as their sensory details, the amount of activity represented in a memory, and so on. The scales were headed by a leadin statement that said either "the memory for the personal event that I have just described" or "the memory fragment that I have just de- scribed." This was followed by a list of the 20 scales, always in the same order. Each consisted of a particular characteristic to be evaluated about the memory in question and then the numbers 1-7, along with verbal descriptions of the two end points. A subject pointed to and clicked on the number judged to be most appropriate for each scale.

Memory reports and final sample of subjects. Two of the authors (D.B. and J.A.R.) independently assessed the validity of the 370 memory reports. They were randomly ordered, and their identification (event or fragment) was concealed from the judges. Each memory description was evaluated against the instructions given to the subjects and was classified as a personal event, a memory fragment, or neither. The judges agreed on $90.0 \%$ of their classifications. They were able to reconcile their differences in all but 3 cases, which were removed from the data sample, along with 57 others, for the following reasons: 28 fragments were considered to be events, 3 events were considered to be fragments, 13 experiences were judged to be repetitive, 4 reports were autobiographical facts, 7 did not contain enough information to decide what kind of memory was being described, and 2 subjects failed to follow instructions in writing their reports. In all, then, 60 reports were rejected. They were provided by 56 subjects. Thus, the final sample consisted of 129 subjects and 258 memory reports. We determined the number of words in each report. Descriptions of events contained significantly more words $(M=73.8)$ than did fragments $[M=34.3 ; F(1,128)=$ $\left.234.17, M S_{\mathrm{e}}=430.18, p<.001\right]$.

The subjects ranged in age from 18.2 to 28.6 years, with a median of 20.2 years. There were 87 females and 42 males. Order of report was counterbalanced, with 65 subjects describing a personal event first and 64 subjects describing a memory fragment first.

\section{Results}

Age estimates and confidence judgments. The subjects estimated that they were younger at the time of their earliest fragment memories than at the time of their earliest event memories. The mean ages were 3.52 years $(S D=1.67)$ and 4.36 years $(S D=1.62)$, respectively $\left[F(1,127)=40.56, M S_{\mathrm{e}}=1.13, p<.001\right]$. Order of report was not statistically significant $[F(1,127)<1]$. Type of memory and order of report interacted. When fragments were described first, the mean estimated age was considerably lower than that for events $[F(1,127)=$ $\left.55.60, M S_{\mathrm{e}}=1.13, p<.001\right]$. When fragments were given second, their age estimates were again lower, although not reliably so $\left[F(1,127)=2.33, M S_{\mathrm{e}}=1.13\right.$, $p>.05]$.

The subjects had reliably less confidence in their estimates of how old they were at the time of fragment experiences than at the time of event experiences. The respective mean confidence ratings were $2.81(S D=1.03)$ and $2.13\left[S D=.88 ; F(1,127)=49.58, M S_{\mathrm{e}}=0.59, p<\right.$ $.001]$. Order of report had no statistically significant effect $\left[F(1,127)=2.98, M S_{\mathrm{e}}=1.18, p>.05\right]$. Memory type and order of report interacted, but simple effects tests disclosed that confidence in age estimates for events was reliably stronger than that for fragments for both report orders $\left[F(1,127)=57.08, M S_{\mathrm{e}}=0.59, p<\right.$ .001 , when events were described first, and $F(1,127)=$ $5.87, M S_{\mathrm{e}}=0.59, p<.05$, when fragments were described first]. ${ }^{2}$

Age distributions of fragment and personal event memories. In view of the interaction of order of report and type of memory on age estimates, we considered 
whether to compare age distributions for fragment and event memories only when each was reported first. However, the difference between the mean ages of memory fragments and personal events when they were reported second ( 3.78 vs. 4.66 years, respectively) was quite similar to the difference when they were reported first (3.26 vs. 4.06 years, respectively). Accordingly, Figure 2 presents cumulative relative frequency distributions of the ages of all memory fragments and all personal event memories (labeled Earliest fragments and Earliest events, respectively). Figure 2 also includes the age distribution for know events from Experiment 1 (Know Experiment 1). It is clear that the distribution for the earliest fragment experiences was substantially lower than that for the earliest event memories. In fact, it was indistinguishable from the distribution for the know events in Experiment 1. The medians of the three distributions were 3.29 years for the earliest fragments, 3.33 years for the know events, and 3.99 years for the earliest events.

Characteristics of fragment and personal event memories. To give a sense of the memory fragments that were obtained, here are two examples, together with the estimated ages (in parentheses) of the subjects at the time of the experiences. "I remember playing in the kitchen sink with a toy army man not really sure how I reached the sink, but I remember that there was music!" ( 2.72 years). "I remember sitting in my parents' bedroom, observing my mother as she did some house cleaning. There is nothing else to the memory, but I re-

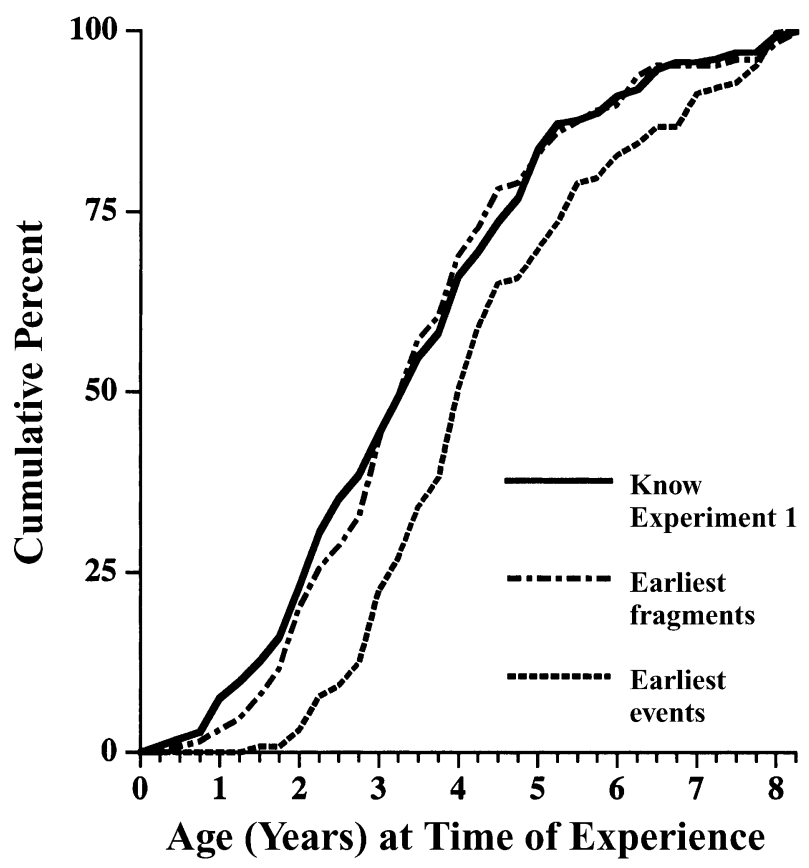

Figure 2. Experiment 2: cumulative relative frequency distributions for the ages of the earliest memory fragments (Earliest fragments) and earliest personal events (Earliest events), compared with the know events from Experiment 1 (Know Experiment 1). member having a very different perspective of the room at the time" (2.39 years).

Figure 3 summarizes the 20 ratings of the two kinds of memories. The horizontal bars are difference scores obtained by subtracting mean memory fragment ratings, which are given in the column to the right of the vertical axis, from the corresponding mean personal event ratings for the 20 scales. The label for the horizontal axis is thus Events - Fragments. The 20 resulting differences are ordered from smallest at the top to largest at the bottom. The vertical axis lists descriptive terms for the 20 scales and, in parentheses, their corresponding scale numbers.

Analyses of variance for each scale revealed that the three smallest differences were not statistically significant. For the 17 remaining scales, ratings were reliably higher for personal event memories [for Scale 3 (smell), $F(1,127)=4.37, M S_{\mathrm{e}}=2.05, p<.05$; for Scale 20 (perspective), $F(1,127)=8.79, M S_{\mathrm{e}}=2.66, p<.01$; and for the 15 remaining differences, $F(1,127) \geq 15.44, M S_{\mathrm{e}} \leq$ $2.90, p<.001]$. Report order also had a significant influence on the ratings in 12 of 20 instances - generally higher when fragment experiences were reported first. As well, report order and memory type produced a significant interaction in the ratings on 8 of the scales. However, none of the interactions was disordinal; that is, ratings were always higher for events than for fragments, regardless of the order in which the subjects gave their reports. In sum, the order effects do not qualify the finding that for 17 of 20 scales, ratings of personal event memories were substantially higher than those of fragment memories.

The ratings indicated that, as compared with memory fragments, remembered personal events possessed more sensory features (smell, visual details, sound, touch, and vividness); were longer, more detailed, higher in activity, and more likely to be thought and talked about; involved superior recollection of the locations and general settings, as well as what happened before and after the experiences; were accompanied by feelings that were better remembered and more intense; and were more likely to be memories in which the subjects saw themselves as participants.

\section{Discussion}

Experiment 2 yielded convincing evidence for two kinds of first remembrances: memories for fragments of experiences and memories for whole events. As compared with event recollections, those of a fragmentary nature were estimated to be from earlier in life, were dated with less confidence, and were different in a number of qualitative respects. The evidence is thus in keeping with the idea that childhood amnesia gives way first to autobiographical recollections of noncontextualized fragments of experiences, rather than to entire episodes.

\section{GENERAL DISCUSSION}

\section{Implications for Theories of Childhood Amnesia}

Although our research cannot be considered to test any theories of childhood amnesia, the findings seem particularly consistent with two hypotheses. One has 


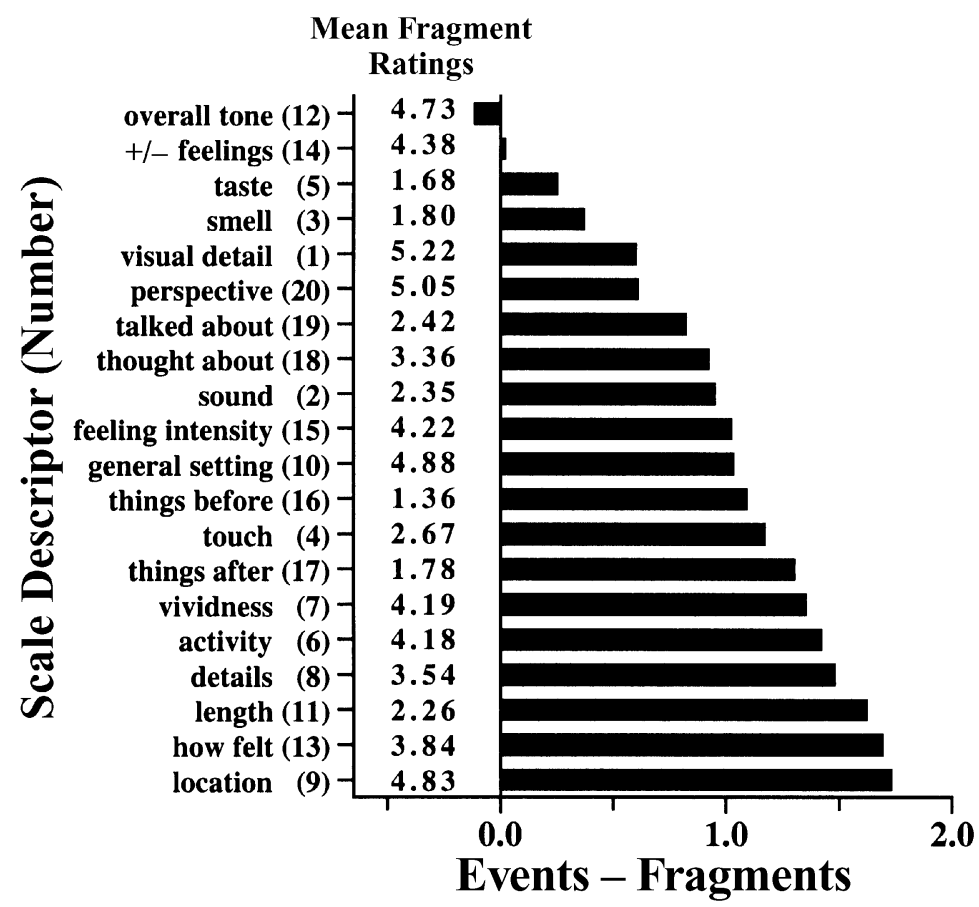

Figure 3. Experiment 2: differences between the mean ratings of 20 characteristics of the earliest remembered personal events (Events) and memory fragments (Fragments).

been proposed by Howe and Courage (Howe, 2000, 2003; Howe \& Courage, 1993, 1997). They contended that the offset of childhood amnesia is brought about by the emergence of the cognitive self around age 2 , a development that permits experiences to be personalized, organized, and retained as autobiographical. The present results cannot tell us whether such a development is the causal factor. Nevertheless, the age distribution of the memory fragments does give some quantitative comfort to the idea: Almost $25 \%$ of them were estimated to be about experiences that had occurred by 2 years of age.

The other theory to which our data apply has been advanced by Pillemer and White (Pillemer, 1998; Pillemer $\&$ White, 1989; White \& Pillemer, 1979). They postulated two functionally different memory systems: a primitive system present from birth, whose representations are images, behaviors, or emotions, and a higher order system that comes into play during the preschool years and encodes events in narrative form. The emergence of the higher order system is seen as marking the end of childhood amnesia. The age and the rating scale differences observed in the present study between fragments and event memories square with the idea of two memory systems, with fragments being retrieved from the primitive system and events from the narrative system.

At the same time, the data point to two adjustments to Pillemer and White's hypothesis. One concerns the claim that the demise of childhood amnesia occurs only when the narrative memory system becomes functional. The earlier datings of first memory fragments, however, suggest that the offset of childhood amnesia precedes the development of narrative competence. Second, Pillemer and White maintained that the contents of the imagistic system are not remembered in a conscious, purposeful manner but only implicitly, as the result of affective and situational cues. Although implicit retrieval may be the rule, the present data indicate that conscious recollection is also possible.

\section{Estimating the Ages of Fragment and Event Memories}

A major concern about the present experiments is that the subjects may have been biased in assigning earlier ages to fragment recollections than to event memories. For example, it is possible that they did so on the grounds of a belief that a fragment, by its very nature, is something that probably originates early in life. Another possibility is that the different datings reflect different characteristics of the two kinds of remembrances. For example, reports of fragments were generally less specific than those of events. As Figure 3 shows, they were briefer, contained fewer details, involved fewer sensory features, and so on. The paucity of such specifics may have led the subjects to infer that fragment experiences must be from an earlier age than are events.

We have conducted an additional study involving the recall of fragments that allows a preliminary assessment of the second of these two possibilities. The investiga- 
tion was identical to Experiment 2 except that the subjects $(n=170)$ provided information using paper and pencil, rather than a computer, and they recollected and dated fragments from the period of $0-8$ years, rather than the earliest fragments that they could remember. The average age of fragments from the 0 - to 8 -year period was 5.07 years, as compared with 3.52 years for the earliest fragments reported in Experiment 2, a highly reliable difference $\left[F(1,295)=63.65, M S_{\mathrm{e}}=2.72, p<.001\right]$. If subjects' estimates of the ages of fragments are influenced by characteristics of the memories (e.g., details or the lack thereof), the ratings of fragments on the 20 scales should likewise be different between the two studies. However, in only five instances did the ratings differ significantly for fragments retrieved from the 0 - to 8-year period, as compared with first fragment memories. In three of those instances, the differences involved features that were indeed vaguer for the earliest fragments: vividness, location of the experience, and how the person felt at the time. On the other hand, many of the scales on which the two sets of fragments did not differ concerned characteristics that might have been anticipated to be important in dating the experiences (e.g., amount of visual detail, sketchiness of details in general, amount of activity involved, and length of the experience). In sum, comparisons between the fragment ratings in the two investigations do not make a convincing case for concluding that it was a lack of detail or anything else inherent in the features of fragments that influenced estimates of their ages or that led them to be dated from earlier in childhood than first event memories.

\section{Memory Fragments, Events Remembered, and Events Known}

Additional clarification of the connection between fragments and event memories may be gained by considering a parallel distinction that exists in a theory about the structure of autobiographical knowledge proposed by Conway and colleagues (Conway, 1996; Conway \& Pleydell-Pearce, 2000; Conway \& Rubin, 1993). The theory postulates three levels of autobiographical knowledge. We restrict our attention to the intermediate and lowest levels. The former is represented by general events that extend over hours, days, or weeks and that can encompass a number of associated episodes. General events correspond to our event or storylike memories. Examples are a day at the beach and a stay in the hospital. At the base level of the structure is event-specific knowledge - what we have labeled as fragments - with durations on the order of seconds or minutes. A remark, a feeling of fear, and a detail of a visual experience are instances of event-specific details. They constitute much of the content of an event memory. Indeed, Conway and Pleydell-Pearce suggested that event-specific details (fragments) are usually contextualized within general events and, if not, are likely to be rapidly forgotten. Although this may be generally the case, the present findings indicate that stand-alone fragments can persist from childhood. We suspect that they can also be remembered from the adult years, although that possibility remains to be documented.

What is the relation between first memories, whether of fragments or events, and happenings that are only known to have been a part of one's past? Autobiographical knowledge may be said to come from two complementary sources. The vast majority of it emerges from the stock of personal experiences from which our autobiographical memories down the road are derived. A considerably smaller part consists of experiences that, by virtue of not having the requisite memory abilities at the time, we cannot remember but may learn about from external sources - parents, photographs, and the like. The former is the past that we can potentially recollect and that gradually comes on line over an interval during childhood; the latter is the past that is blanketed by childhood amnesia and that correspondingly diminishes over the same period of time.

Our objective in the present research has been to provide a more accurate mapping of the boundary between the two domains. We have tried to do so from both sides of the divide - that is, by determining age distributions for events from childhood for which one is amnesic and for the earliest personal memories that can be retrieved, which the present investigation suggests are fragments. In principle, this should be possible, and the two distributions should line up. Achieving this objective in practice is another matter. With specific reference to the present research, it is not difficult to raise concerns about whether the age distribution of know events obtained in Experiment 1 is a true indication of the decline of childhood amnesia. The fact that it was indistinguishable from the age distribution for fragments in Experiment 2 may seem to confirm that it is a valid indicator, but we suspect that the similarity of the two distributions is only a pretty coincidence. On the other hand, we do feel quite confident in claiming that the age distribution of the earliest fragment memories gives a truer measure of waning childhood amnesia than does the comparable age distribution for the earliest episodic memories. In our view, the latter overestimates the reach of childhood amnesia.

\section{The End of Childhood Amnesia}

If this claim is conceded, we can now determine the typical age at which the hegemony of childhood amnesia gives way to the dominance of retrievable personal memories of childhood. We propose a threshold approach to the task (see Usher \& Neisser, 1993, for comparable reasoning). In the context of an age distribution of the earliest fragment memories, the threshold may be taken as the age beyond which $50 \%$ of the fragment experiences are estimated to have occurred. Thus, Experiment 2 suggests 3.29 years (the median age of the earliest fragment memories) as a realistic estimate of the age of offset of childhood amnesia, as opposed to $4-5$ years, which is what we had proposed earlier (Bruce et al., 2000).

A possible challenge to our conclusion that fragments mark the end of childhood amnesia comes from research by Usher and Neisser (1993) and Eacott and Crawley 
(1998). Both studies reported that adults could accurately answer questions about events that happened to them between ages 2 and 3 - for example, the birth of a younger sibling. However, it is debatable whether the answers to such questions should be construed as episodic memories as we have described them here. In our judgment, it is more persuasive to consider them as bits and pieces of memories - in other words, as memory fragments.

\section{REFERENCES}

Bruce, D., Dolan, A., \& Phillips-Grant, K. (2000). On the transition from childhood amnesia to the recall of personal memories. Psychological Science, 11, 360-364.

CoNWAY, M. A. (1996). Autobiographical memories and autobiographical knowledge. In D. C. Rubin (Ed.), Remembering our past: Studies in autobiographical memory (pp. 67-93). Cambridge: Cambridge University Press.

Conway, M. A., \& Pleydell-Pearce, C. W. (2000). The construction of autobiographical memories in the self-memory system. Psychological Review, 107, 261-288.

ConWAY, M. A., \& RUBIN, D. C. (1993). The structure of autobiographical memory. In A. E. Collins, S. E. Gathercole, M. A. Conway, \& P. E. M. Morris (Eds.), Theories of memory (pp. 103-137). Hove, U.K.: Erlbaum.

Dudycha, G. J., \& Dudycha, M. M. (1933a). Adolescents' memories of preschool experiences. Journal of Genetic Psychology, 42, 468-480.

Dudycha, G. J., \& Dudycha, M. M. (1933b). Some factors and characteristics of childhood memories. Child Development, 4, 265-278.

Eacott, M. J., \& Crawley, R. A. (1998). The offset of childhood amnesia: Memory for events that occurred before age 3. Journal of Experimental Psychology: General, 127, 22-33.

GARDINER, J. M., \& RICHARDSON-KLAVEHN, A. (2000). Remembering and knowing. In E. Tulving \& F. I. M. Craik (Eds.), The Oxford handbook of memory (pp. 229-244). Oxford: Oxford University Press.

Howe, M. L. (2000). The fate of early memories: Developmental science and the retention of childhood experiences. Washington, DC: American Psychological Association.

Howe, M. L. (2003). Memories from the cradle. Current Directions in Psychological Science, 12, 62-65.

Howe, M. L., \& Courage, M. L. (1993). On resolving the enigma of infantile amnesia. Psychological Bulletin, 113, 305-326.

Howe, M. L., \& CouRAGE, M. L. (1997). The emergence and early development of autobiographical memory. Psychological Review, 104, 499-523.

Johnson, M. K., Foley, M. A., Suengas, A. G., \& Raye, C. L. (1988). Phenomenal characteristics of memories for perceived and imagined autobiographical events. Journal of Experimental Psychology: General, 117, 371-376.

KoTRE, J. (1995). White gloves: How we create ourselves through memory. New York: Free Press.

MalinOSKI, P., LYNN, S. J., \& Sivec, H. (1998). The assessment, validity, and determinants of early memory reports: A critical review. In S. J. Lynn \& K. M. McConkey (Eds.), Truth in memory (pp. 109-136). New York: Guilford.

MiLes, C. (1893). A study of individual psychology. American Journal of Psychology, 6, 534-558.

MULLEN, M. K. (1994). Earliest recollections of childhood: A demographic analysis. Cognition, 52, 55-79.

Multhaup, K. S., Johnson, M. D., \& Tetirick, J. C. (2005). The wane of childhood amnesia for autobiographical and public event memories. Memory, 13, 161-173.

Naвокоv, V. (1966). Speak, memory: An autobiography revisited (rev. ed.). New York: Putnam.

O'Keeffe, G. (1977). Georgia O'Keeffe. New York: Penguin. (Original work published 1976).

Pillemer, D. B. (1998). Momentous events, vivid memories. Cambridge, MA: Harvard University Press.

Pillemer, D. B., \& White, S. H. (1989). Childhood events recalled by children and adults. In H. W. Reese (Ed.), Advances in child devel- opment and behavior (Vol. 21, pp. 297-340). Orlando, FL: Academic Press.

RoBinson, J. A. (1992a). Autobiographical memory. In M. M. Gruneberg $\&$ P. E. Morris (Eds.), Aspects of memory: Vol. 1. The practical aspects (2nd ed., pp. 223-251). London: Routledge.

Robinson, J. A. (1992b). First experience memories: Contexts and functions in personal histories. In M. A. Conway, D. C. Rubin, H. Spinnler, \& W. A. Wagenaar (Eds.), Theoretical perspectives on autobiographical memory (pp. 223-239). Dordrecht: Kluwer.

Rubin, D. C. (1982). On the retention function for autobiographical memory. Journal of Verbal Learning \& Verbal Behavior, 21, 21-38.

Rubin, D. C. (2000). The distribution of early childhood memories. Memory, 8, 265-269.

SALAMAN, E. (1970). A collection of moments: A study of involuntary memories. London: Longman.

Tulving, E. (1983). Elements of episodic memory. Oxford: Oxford University Press, Clarendon Press.

Tulving, E. (1985). Memory and consciousness. Canadian Psychology, 26, 1-12.

UsHer, J. A., \& NeISSER, U. (1993). Childhood amnesia and the beginnings of memory for four life events. Journal of Experimental Psychology: General, 122, 155-165.

WALDFOGEL, S. (1948). The frequency and affective character of childhood memories. Psychological Monographs, 62 (Whole No. 291).

WetZler, S. E., \& Sweeney, J. A. (1986). Childhood amnesia: An empirical demonstration. In D. C. Rubin (Ed.), Autobiographical memory (pp. 191-201). Cambridge: Cambridge University Press.

White, S. H., \& Pillemer, D. B. (1979). Childhood amnesia and the development of a socially accessible memory system. In J. F. Kihlstrom \& F. J. Evans (Eds.), Functional disorders of memory (pp. 29-73). Hillsdale, NJ: Erlbaum.

WiLson, E. O. (1994). Naturalist. Washington, DC: Island Press.

Woolf, V. (1976). Moments of being: Unpublished autobiographical writings (J. Schulkind, Ed.). New York: Harcourt Brace Jovanovich.

\section{NOTES}

1. The contrast between autobiographical knowledge arising from a personal memory and that arising from an external source is consistent with the distinction that Tulving (1985) initially drew between remembering an event and knowing "in some other way that it occurred" (p. 6). Tulving's contention was that a remembered event is associated with a subjective state of self-knowing and a known event with a state of knowing not based on a personal memory. Over the years, the distinction has changed. Remembering has retained Tulving's meaning, but knowing has come to be viewed as equivalent to a feeling of familiarity about the past occurrence of an event (e.g., Gardiner \& RichardsonKlavehn, 2000, p. 240). In our judgment, however, a feeling of familiarity is also based on self-knowing. In short, the difference between remembering and knowing has become a contrast between different kinds of self-knowing. Because our meaning of the terms remember and know is in keeping with what Tulving originally meant by them, we have elected to use them in the present report. We doubt that this will prove confusing. The reader need only hold tight to the idea that our know events have no feeling of familiarity about them.

2. It should be pointed out that the event memory instructions in the two experiments were slightly different. In Experiment 1, we were concerned that the subjects understand the distinction between remember and know events. Thus, the instructions for a remember event emphasized being able to be consciously aware of it again. In Experiment 2, the intent was to communicate the difference between a fragment and an event memory. Therefore, the instructions stressed the storylike quality of an event memory. For this reason, perhaps, descriptions of first event memories were longer in Experiment 2 than in Experiment 1, albeit only marginally: means of 73.8 versus 63.1 words, respectively. On the other hand, the mean age estimates of first event memories in Experiments 1 and 2 were quite similar (4.22 and 4.36 years, respectively), as were mean confidence judgments in those estimates (2.08 and 2.13, respectively). In sum, the data suggest that the subjects perceived first event memories in a similar way in both experiments, regardless of whether we emphasized that the remembrances are of things that can be consciously reexperienced or that the memories are like stories. 


\section{APPENDIX}

The 20 Rating Scales Used to Assess Characteristics of Personal Event Memories

Note: The assessment form used for memory fragments was the same, except for the wording changes indicated in parentheses. Each item is followed by the descriptions of the end points of the scale; the numbers 1-7, separating the end points, have been omitted.

The memory for the personal event that I have just described (The memory fragment that I have just described):

1. involves visual detail: little or none-a lot

2. involves sound: little or none-a lot

3. involves smell: little or none-a lot

4. involves touch: little or none-a lot

5. involves taste: little or none-a lot

6. involves activity: little or none-a lot

7. the overall vividness of the memory (memory fragment) is: vague-very vivid

8. the details of the personal event (memory fragment experience) are: sketchy-very detailed

9. the location of the personal event (memory fragment experience) is: vague-clear/distinct

10. the general setting is: unfamiliar-familiar

11. the personal event (memory fragment experience) seems: short-long

12. the overall tone of the memory (memory fragment) is: negative-positive

13. I remember how I felt at the time of the personal event (memory fragment experience): not at all-definitely

14. my feelings at the time were: negative-positive

15. my feelings at the time were: not intense-very intense

16. I remember things that took place immediately before the personal event (experience): not at all-very clearly

17. I remember things that took place immediately after the personal event (experience): not at all-very clearly

18. since this personal event (experience) occurred, I have thought about it: not at all-many times

19. since this personal event (experience) occurred, I have talked about it: not at all-many times

20. I see my memory of the personal event (memory fragment experience) from the perspective of: a participant-a spectator

(Manuscript received January 2, 2004;

revision accepted for publication August 1, 2004.) 